удк 316.733

\title{
ПРОСЬЮМЕРСКИЕ ПРАКТИКИ В КОНТЕКСТЕ АКТОРНО-СЕТЕВОЙ ТЕОРИИ БРУНО ЛАТУРА
}

\author{
Гиниятова Елена Владимировна, \\ evg@tpu.ru \\ Национальный исследовательский Томский государственный университет, \\ Россия, 634050, г. Томск, пр. Ленина, 36.
}

Гиниятова Елена Владимировна, кандидат философских наук, старший научный сотрудник Лаборатории методологии и теории культуры Института искусств и культуры Национального исследовательского Томского государственного университета.

В современном гуманитарном дискурсе и концепция просьюмеризма, и акторно-сетевая теория Б. Латура не теряют своей остроты, поскольку оба эти феномена предлагают новый взгляд на социальное и место человека в нем. Так, благодаря акторно-сетевой теории, возникает понятие симметричной антропологии, а просьюмеризм, формирующийся как ответная реакция на субъекта общества потребления, предлагает альтернативу тотальному потреблению. В связи с этим цель статьи - применение некоторых принципов акторно-сетевой теории к анализу современных просьюмерских практик (таких как социальное предпринимательство) - представляется достаточно актуальной. Метод, который использовался для достижения обозначенной цели, - сравнительно-аналитический. В результате было выявлено, что при рассмотрении просьюмерских практик с применением методологии акторно-сетевой теории нивелируется ряд принципиальных положений, формирующих специфику такой разновидности просьюмеризма, как, например, социальное предпринимательство.

Ключевые слова: Общество потребления, просьюмеризм, социальное предпринимательство, акторно-сетевая теория.

Для того чтобы реализовать цель, заложенную уже в самом названии данной статьи, необходимо прояснить два концептуальных понятия - просьюмеризм и акторносетевая теория.

Просьюмеризм неразрывно связан с феноменом общества потребления, описанного Г. Маркузе и Ж. Бодрийяром $[1,2]$. Общество потребления порождает человека одномерного (и воспроизводится им же), использующего вещи не столько в их функциональном назначении, сколько в контексте их символических надстроек, которые, в частности, позволяют субъекту отождествлять себя с желаемым и транслировать свой идеальный, «нашпигованный» нужными коннотациями, образ в социум. Именно в обществе потребления достигают своего апогея такие демонстрационные стратегии, как брендоориентированность, трансэстетизация, лукизм и т. д. Выступая пассивным потребителем, субъект общества потребления объективирует себя в этом процессе дважды: первый раз - объективируя и отчуждая свой труд в товарно-денежных отношениях, второй - в процессе потребления. Подобная двойная объективация негативно влияет на экзистенциональное измерение человеческого бытия и прежде всего на его идентичность. Персональная идентичность одномерного человека общества потребления растворяется в коллективной, социальной. Проводя аналогии, можно утверждать, что в обществе потребления субъекту приоритетнее казаться, чем быть. 
Просьюмеризм - это ответная реакция на общество потребления и его субъекта. Просьюмер не просто потребляет, он производит. Более того, его потребление начинает носить осознанный характер [3], возвращая вещам их сущностную характеристику вещность [4]. В рамках просьюмеризма производство является свободным актом волеизъявления, ломая принципы капиталистической логики. Находясь в процессе необремененного рыночными установками производства товаров/услуг, просьюмер трансформирует собственное Я, конструирует и подвергает пересборке персональную идентичность $[5,6]$. При этом просьюмерская деятельность, как и любая другая, имеет коммуникативный характер. Она объединяет единомышленников, и тогда, формируя и оттачивая общее ценностно-смысловое пространство, можно говорить и о работе с групповой идентичностью. Включение в просьюмерскую деятельность двух типов идентичности согласуется с концепцией модели идентичности, которую предлагают В.Е. Буденкова и Е.Н. Савельева [7], согласно которой связь персональной и коллективной (групповой/микросоциальной) идентичностей неразрывна и складывается по принципу коммуникации и движения от индивидуального к коллективному.

Таким образом, в социально-культурном плане благодаря просьюмеризму начинают формироваться новые ценностно-смысловые паттерны восприятия производства и потребления; происходит «реабилитация» персональной идентичности, выхолощенной обществом потребления до транслируемого во вне образа и открываются возможности для ее пересборки; более отчетливо проявляется связь персональной и коллективной идентичности, а также влияние первой на формирование второй; увеличивается значимость индивидуального труда как формы деятельности, способствующей самовыражению и установлению новых коммуникативных связей.

Из всего многообразия просьюмерских практик особое внимание хотелось бы уделить социальному предпринимательству [8]. Стоит отметить, что это наиболее спорный вид просьюмерской деятельности, поскольку само наличие термина «предпринимательство» отсылает нас к рыночной модели, к получению прибыли. Тем не менее смысловой доминантой в определении социального предпринимательства является именно ориентация на возможность решения социальных проблем, а не последующая капитализация продуктов/услуг, полученных в результате деятельности. К ключевым характеристикам социального предпринимательства стоит отнести следующие:

« - преобладание социальной цели над получением экономического эффекта от деятельности;

- решение (ослабление остроты) реально существующей социальной проблемы, на которое направлена деятельность организации;

- самоокупаемость и финансовая устойчивость организации обеспечиваются преимущественно продажей товаров или услуг (а не получением грантов либо иной формой помощи внешних благотворителей);

- наличие инновации в достижении результатов деятельности (социальная или экономическая инновация, инновационная комбинация социальных, материальных, финансовых ресурсов и пр.)» [9, с. 262].

Таким образом, можно сказать, что к социальному предпринимательству относится деятельность людей/организаций (чаще всего - НКО), ставящих основной задачей своего функционирования не извлечение прибыли, а решении какой-либо социальной проблемы новаторскими способами, которое впоследствии можно алгоритмизировать и тиражировать как успешную практику. Что немаловажно, социальное предпринимательство не ориентировано на прибыль, а только на самоокупаемость. Но не только это является основанием считать социальное предпринимательство просьюмерской прак- 
тикой, а еще и то, что социальное является триггером инициирования производственной деятельности, актуализируя субъекта как активного и преобразующего реальность.

Акторно-сетевая теория [10], методологию которой мы собираемся применить к анализу социального предпринимательства, сформировалась в рамках области исследований науки и технологий (STS). Данная теория является вызовом для дискурсивного пространства гуманитарных наук. Это связано с ключевым тезисом акторно-сетевой теории, который предлагает рассматривать все объекты и субъекты материального миpa, в том числе и животных - т. е. не людей (nonhumans), как полноценных участников/агентов социальных отношений и систем. Этот оспариваемый тезис акторносетевой теории становится конституирующим принципом новой, плоской онтологии, которая лишена антропоцентричности, поскольку все объекты и субъекты являются однопорядковыми и рядоположенными участниками/агентами социальных отношений. Можно сказать, что онтология акторно-сетевой теории как минимум предлагает нам отсутствие социального в традиционном понимании и новую симметричную антропологию.

Рассматривая в разрезе акторно-сетевой теории практик просьюмеризма, а именно социального предпринимательства, мы сталкиваемся с изменением интерпретационных полей данного явления. Эта деятельность и ее понимание сформированы в контексте традиционных субъект-объектных отношений, где есть активный действующий субъект и трансформирующийся, познаваемый объект. В контексте акторно-сетевой теории социальное предпринимательство лишается как минимум двух своих интерпретационных оснований:

- доминирующего процессуально-активного действующего субъекта, поскольку взаимодействие происходит обоюдно-трансформирующее. Другими словами, инициатором социальных отношений могут выступать не только люди/организации, но и объекты нематериального мира, не люди. И эти онтологически легитимированные акторы становятся субъектами формирования новых социальных практик и трансакций, а также инициируют новые подходы к решению социальных проблем;

- вторым важным сдвигом становится невозможность алгоритмизировать решение социальных проблем с их последующим тиражированием на другие институции (в традиционном понимании) и других акторов (в рамках акторно-сетевой теории). Каждый раз формируется новая, уникальная сеть с новыми уникальными акторами и стратегиями взаимодействия. И здесь мы уже говорим о перформативном характере формирования сообщества в процессе реализации деятельности, где сообщество отличается неустойчивостью постоянно меняющихся связей (реляционность).

Исследование выполнено за счет гранта Российского научного фонда (проект No19-18-00237).

\section{СПИСОК ЛИТЕРАТУРЫ}

1. Маркузе Г. Одномерный человек - М.: АСТ, Ермак, 2003. - 331 с.

2. Бодрийяр Ж. Общество потребления. - М.: АСТ, 2019. - 320 с.

3. Потоцкая А. Осознанное потребление: что это такое и почему о нём нужно задуматься каждому. URL: https://lifehacker.ru/osoznannoe-potreblenie/ (дата обращения 12.09.2020).

4. Хайдеггер М. Исток художественного творения. - М.: Академический проект, 2008. - 528 с.

5. Гиниятова Е.В. Современные социально ориентированные практики и конструирование идентичности: области взаимодействия // Векторы благополучия: экономика и социум. - 2019. - № 4 (35). C. 101-104. URL: https://jwt.su/journal/article/view/1008/1020 (дата обращения 12.09.2020).

6. Конева А.В., Лисенкова А.А. Матрица идентичности в цифровую эпоху: социальные вызовы преодоления анонимности // Вестник Томского государственного университета. Культурология и искусствоведение. - 2019. - № 35. - C. 14-28. URL: http://journals.tsu.ru//culture/\&journal_page=archive\&id= 1895\&article_id=42635 (дата обращения 12.09.2020). 
7. Буденкова В.Е., Савельева Е.Н. Идентичность как предмет теоретико-методологического анализа: модели и подходы // Вестник Томского государственного университета. Культурология и искусствоведение. - 2016. - № 1 (21). - С. 31-44.

8. Waddock S., Post J. Social entrepreneurs and catalytic change // Public Administration Review. - 1991. V. 51. - № 5. - P. 393-402.

9. Социальное предпринимательство в России и в мире: практика и исследования / отв. ред. А.А. Московская. - М.: ИД Высшей школы экономики, 2011. - 284 с.

10. Латур Б. Пересборка социального: введение в акторно-сетевую теорию - М.: ИД Высшей школы экономики, 2014. - 384 с.

Поступила 12.12.2020 2. 
удк 316.733

\title{
PROSUMER PRACTICES IN THE CONTEXT OF B. LATOUR'S ACTOR-NETWORK THEORY
}

\author{
Elena V. Giniyatova, \\ evg@tpu.ru
}

National Research Tomsk State University, 36, Lenin avenue, Tomsk, 634050, Russia.

Elena V. Giniyatova, Cand. Sc., senior researcher, National Research Tomsk State University.

In modern humanitarian discourse, both the concept of prosumerism and the actor-network theory of B. Latour do not lose their sharpness, since both of these phenomena offer a new view of the social and the place of man in it. So, thanks to the actor-network theory, the concept of symmetric anthropology arises, and prosumerism, which is formed as a response to the subject of the consumer society, offers an alternative to total consumption. In this regard, the purpose of the article - the application of some principles of the actor-network theory to the analysis of modern pro-Sumer practices (such as social entrepreneurship) - seems to be quite relevant. The method used to achieve the designated goal is comparative-analytical. As a result, it was revealed that when considering prosumer practices using the methodology of the actor-network theory, a number of fundamental provisions are leveled that form the specifics of such a kind of prosumerism, such as social entrepreneurship.

Key words: Consumer society, prosumerism, social entrepreneurship, actor-network theory.

Research was carried out with a grant from the Russian Science Foundation (project no. 19-18-00237).

\section{REFERENCES}

1. Markuze G. Odnomerny chelovek [One-dimensional man]. Moscow, AST Publ., Yermak Publ., 2003. 331 p.

2. Baudrillard J. Obshchestvo potrebleniya [Consumer Society]. Moscow, AST Publ., 2019. 320 p.

3. Pototskaya A. Osoznannoe potreblenie: chto eto takoe i pochemu o nem nuzhno zadumatsya kazhdomu [Conscious consumption: what it is and why everyone needs to think about it]. Available at: https://lifehacker.ru/osoznannoe-potreblenie/ (accessed 12 September 2020).

4. Heidegger M. Istok khudozhestvennogo tvoreniya [The source of artistic creation]. Moscow, Akademicheskiy proekt Publ., 2008. 528 p.

5. Giniyatova E.V. Modern socially-oriented practices and identity design: areas of interaction. Journal of Wellbeing Technologies, 2019, no. 4 (35), pp. 101-104. In Rus. Available at: https://jwt.su/journal/article/view/1008/1020 (accessed 12 September 2020).

6. Koneva A.V., Lisenkova A.A. Identity matrix in the digital age: social challenges to overcome the anonymity. Tomsk State University Journal of Cultural Studies and Art History, 2019, no. 35, pp. 14-28. In Rus. Available at: http://journals.tsu.ru//culture/\&journal_page=archive\&id=1895\&article_id=42635 (accessed 12 September 2020).

7. Budenkova V.E., Saveleva E.N. Identity as a topic of theoretical and methodological analysis: models and approaches. Tomsk State University Journal of Cultural Studies and Art History, 2016, no. 1 (21), pp. 31-44. In Rus.

8. Waddock S., Post J. Social entrepreneurs and catalytic change. Public Administration Review, 1991, vol. 51, no. 5 , pp. 393-402.

9. Sotsialnoe predprinimatelstvo v Rossii i v mire: praktika i issledovaniya [Social entrepreneurship in Russia and in the world: practice and research]. Ed. by A.A. Moskovskaya. Moscow, HSE Publ., 2011. 284 p.

10. Latour B. Peresborka sotsialnogo: vvedenie v aktorno-setevuyu teoriyu [Rebuilding the Social: An Introduction to Actor-Network Theory]. Moscow, HSE Publ., 2014. 384 p.

Received: 12 December 2020. 